\title{
Escuela e identidad: Un desafío docente para la cohesión social
}

\author{
Silvia Redón Pantoja \\ Universidad Católica de Valparaíso, Valparaíso, Chile. \\ Email: silvia.redon@ucv.cl
}

Resumen: La investigación que se expone, realizada en $\mathrm{Chile}^{1}$, se vincula a la vivencia de ciudadanía en niños y niñas en el espacio escolar, a través de la configuración de "lo común” como plataforma de cohesión social. El diseño metodológico corresponde a estudio de casos múltiples, correspondiente a ocho centros escolares de primaria. El análisis de los registros de observación, entrevistas y documentos, nos permitieron levantar tres grandes categorías: La categoría denominada, "alteridad” con las subcategorías de sumisión/ dominación, discriminación por género y estética. La segunda gran categoría llamada: "lo común”, con líneas discursivas vinculadas al sentido de pertenencia, participación, democracia, sociabilidad y control normativo. Y por último, "Identidad", vinculada a prestigio social y autonomía versus dependencia. Los estudiantes configuran distintas identidades de prestigio social según clase, el cual obedece a un estereotipo normativo configurado por el adulto, como formas de control para el mantenimiento del orden desde el "poder oficial" en la escuela y que impacta en el horizonte ideológico, ético político de las representaciones simbólicas de niños y niñas de ausencia de vivencia de ciudadanía en la escuela primaria.

Palabras clave: alteridad, lo común, identidad, cohesión social

\section{School and Identity: An educational challenge for social cohesion}

Abstract: The present research, that took place in Chile, refers to children's citizenship experience in the realm of school, through the configuration of 'the common' as a social cohesion platform. The methodological design is a case study in eight primary level educational centres. The data analysis from observation, interviews, and documents, results in three main categories: the first is the "alterity" (otherness) with the subcategories submission/domination, gender discrimination and aesthetics. The second large category is "the common", related to the discursive lines of ownership, participation, democracy, sociability and normative control. And the last is 'identity' related to social prestige, and autonomy versus dependency. The students build different prestige's identities according to social class. The identities match with a normative stereotype modelled by the adult, as control mechanisms to maintain order in school from the 'established power'. This control impacts the ideological, ethical and political horizon of the children's symbolic representations, that are experienced by them as the lack of citizenship in the primary school.

Key words: otherness, the common, identity, social cohesion 


\section{Escola e Identidade: Um desafio para o ensino da coesão social}

Resumo: A pesquisa mostrada, realizada no Chile, está ligada à experiência de cidadania em crianças no ambiente escolar, através da definição de "comuns" como uma plataforma para a coesão social. O desenho metodológico corresponde a estudos de casos múltiplos, o que corresponde a oito escolas de ensino fundamental. A análise dos registros de observação, entrevistas e documentos, nos permitiu construir três grandes categorias: A categoria chamada de "alteridade", com as subcategorias de submissão / dominação, discriminação de gênero e estética. A segunda categoria grande chamado “comum” linhas discursivas ligadas a um sentimento de pertença, participação, democracia, sociabilidade e controle regulamentar. E, finalmente, "Identidade”, ligada ao status social e autonomia versus dependência. Os estudantes configuram diferentes identidades de prestígio social conforme classe, que segue um conjunto de pressupostos normativos configurado pelo adulto, como uma forma de controle para a manutenção da ordem a partir do "poder oficial” na escola e que impacta no horizonte ético e político ideológico das representações simbólicas das crianças na ausência de experiência de cidadania na escola primária.

Palavras-chave: alteridade, o comum, identidade, coesão social

$* * *$

\section{Introducción}

Los resultados de investigación que se exponen en este artículo, responden a los objetivos por: conocer y comprender las prácticas de ciudadanía y cohesión social presentes en niños y niñas, en el espacio escolar como "morada de lo común”. Para el logro de este objetivo se indagó a través de un diseño de estudios de casos múltiple, en ocho centros escolares, con diferentes plataformas de contexto de habla situada en lo socioeducativo y socio-económico.

El presente artículo se organiza con la siguiente estructura: Al inicio se definen y discuten los conceptos de ciudadanía y cohesión social, como prácticas que surgen desde un una identidad de estudiante que se construye en la escuela. Una vez aclarados los conceptos, se expone la metodología utilizada para recoger información de campo, desde una epistemología hermenéutica que argumenta el diseño utilizado y los criterios de selección en las unidades de "Casos” utilizadas para el estudio.

Por último, se da cuenta y explicitan los procesos analíticos que conducen a categorías emergentes producto de las fuentes de informantes, explicitando los mecanismos por los cuales se configuran las prácticas y representaciones simbólicas de cohesión social traducidas en líneas discursivas vinculadas a la identidad como "prestigio social”, sentido de pertenencia, sentido de lo común, sentido de seguridad, en la construcción de subjetividad en la infancia. 


\section{Planteamiento del problema y preguntas de investigación}

Este proyecto de investigación surge por la necesidad de indagar en la escuela como espacio de subjetivación en la construcción de identidad, como cimiento en la constitución de "lo común” (sentido político).

Esta necesidad indagatoria nos lleva a preguntarnos: ¿Desde qué terreno identitario forjan la comunidad los infantes? ¿Qué iniciativas se movilizan en los espacios de recreo para aunar el sentido de lo común? ¿Cómo surgen desde la naturalidad, las formas de relacionarse? ¿Qué es lo común entre niños y niñas? ¿A qué configuración identitaria obedece el interés por lo común? ¿Qué proyecto común los aúna? ¿Qué valoran como "bien común?.

Éstas y otras interrogantes, resaltan una urgencia por conocer lo que piensan, sienten y hacen niños y niñas para forjar redes vinculares de cohesión social y levantar las categorías que describan la configuración en sus representaciones simbólicas identitarias en la construcción de lo común, sustentada en una convivencia aunada por un "algo" (idea, valor, emoción, objetivo, proyecto) que los cohesiona o la inexistencia del mismo.

\section{Marco teórico y definición de categorías conceptuales}

La discusión teórica, escuetamente sitúa los conceptos que sostienen esta problemática de estudio: Escuela e identidad, entendiendo la identidad como el cimiento que subyace a un proyecto común y cómo dialéctica permanente social-personal en la vida de los sujetos, cuya "morada" o espacio de lo común "institucionalizada" se denomina escuela, capturando o albergando al sujeto en un itinerario vital por más de doce años.

\section{La Escuela:}

La definición de la escuela, como institución escolar, no está explicada desde su itinerario histórico ${ }^{2}$, tampoco desde su componente curricular como intencionalidad pedagógica. Sin embargo, cabe destacar que la escuela en sus inicios, surge como un privilegio de elite, vinculada al poder de la Iglesia ${ }^{3}$ y/o a particulares, tan sólo en los dos últimos siglos, se responsabiliza al estado, como su deber en la tarea por masificar el proceso educativo a toda la población y como derecho ciudadano ${ }^{4}$.

La escuela desde la modernidad, constituye un espacio público, en el cual la sociedad y sus representaciones en el Estado se configuran y redefinen. ${ }^{5}$. Desde esta perspectiva en el contexto escolar se producen y reproducen las significaciones sociales y políticas macro y micro que constituyen la vida social política de los sujetos y sus identidades. "El factor sustancial que regula las relaciones en la escuela, lo constituye las relaciones de poder la existencia de dependencia entre profesorado y 
alumnado, la vivencia de la dominación la resistencia ante el poder autoritario" (Martínez. J, 2005: 17). La escuela como nicho de relaciones interpersonales, ha sido un proceso de construcción histórica desde los Estados Nacionales del siglo XIX. El panóptico desde ese entonces, cubría todas las dimensiones de la sociedad. Con un fin homogenizador, la cárcel, el ejército, la escuela, la iglesia, en fin, la vida cotidiana misma fue objeto del control, la vigilancia y el castigo. "El panóptico es una máquina maravillosa que, a partir de deseos de lo más diferentes, fabrica efectos de poder homogéneos” ${ }^{6}$ (Foucault 2009: 234) Una ciudadanía imaginada, fabricada en estas instituciones, al servicio de intereses de las elites, llamadas imperios del colonialismo. En nuestro país, el proceso tiene matices en la historia chilena, que transita desde un presidente que proclama el lema: "gobernar es educar" " hasta llegar a una dictadura ${ }^{8}$ en la que apagar las conciencias y desincentivar la práctica ciudadana se disfrazaron en la "escuela” bajo la lógica instrumental de un currículum racio-técnico excluyente y silenciador de la escuela pública.

La cultura escolar ${ }^{9}$ entendida como el conjunto de prácticas y simbolizaciones construidas en la escuela, se encuentra hoy afectada predominantemente por el cruce de dos culturas; una asociada a la tradición atrapada en el control, la vigilancia y el castigo reproducido por el propio sistema educativo y otra emergente del contexto social contingente, que promueve desde los códigos del mercado un individualismo que repercute en las "formas de trato", guiada por una lógica que instrumentaliza las relaciones humanas, debilitando con ello, el sentido de lo público, como bien común.

La escuela, también ha perpetuado un concepto de infancia o de joven, que desde su devenir histórico desde fines del siglo XIX hasta la actualidad, se ha definido como "naturaleza” biológica-psicológica, de estadios, rótulos y definiciones organizadas en corpus teóricos heredados de la ciencia positiva, observándolo como fenómeno natural más que construcción social. A lo anterior, se agrega además un enfoque escolar de "aprestamiento" y preparación para la formación cognitiva que contribuya a largo plazo a la inserción económica laboral y a la "integración-reproducción” del sistema social imperante.

Una sociedad democrática vigorosa, necesita desarrollar en sus miembros la idea que se trata de un proyecto común, que compromete en su construcción a todos los contemporáneos, pero en la que también los que ya se fueron pusieron su parte y en la que los que vendrán pondrán la suya. Ese tipo de compromiso cívico sobre el que se soporta la democracia, requiere que los miembros de la sociedad se sientan vinculados con las demás personas que forman parte de su comunidad. Nada de eso, puede ser alcanzado sin una experiencia escolar que induzca en los niños y en los jóvenes las virtudes más básicas de la vida compartida y los provea, al mismo tiempo, de una identidad común emergente de sólidas identidades personales, que les permita tejer lealtades entre sí y reconocerse como iguales en una comunidad que los contiene. (Peña 2004). ${ }^{10}$ 
El Centro escolar entendido como cultura de agencia de simbolización y subjetivación; de asociatividad asegurada por la institucionalidad obligatoria de Deber y Derecho público, de vivencia de la identidad y la alteridad, supone un proyecto educativo que plantee vivir la pluralidad cultural, desarrollando los valores de solidaridad, igualdad, respeto, y justicia, para superar cualquier tipo de discriminación y permitir, la formación para laprevención de conflictos en todos los ámbitos de la vida personal, familiar y social. "Los países requieren ciudadanos, capaces de tener lealtades entre ellos y dispuestos a cumplir las reglas. Esto aportará confianza y cohesión social, tanto intra-grupos como inter-grupos. Y nada de eso se logra, o se explica, cuando concebimos la política como un simple intercambio" 11 (Peña: 2007). Los infantes están invisibilizados por su condición de tal, sin embargo, son ellos y ellas, los que en años posteriores les tocará asumir la herencia que la escuela ha forjado como construcción de un proyecto de bien-estar común, como ciudadanos responsables en la lectura del mundo y re-configuración del mismo, en sus dimensiones sociales.

La vivencia de la democracia, emergente de la autonomía de los sujetos, la experiencia de lo común en acciones, sentidos y políticas de participación se aprenden o se silencian (desaprenden) en la escuela. La consolidación de una identidad personal, como cimiento en la forma de relacionarse (alteridad) para construir "lo común” y el sentido valorativo de "bien común" como lo político, requieren de un docente capaz de inspirar en este gran desafío de transformación social-personal.

Hoy los itinerarios de vida de los sujetos están capturados en el bucle: metro-trabajo-tele-cama (Castodiaris 2002): ¿Qué hacer? El panorama se observa borroso al observar un empobrecimiento de lo humano expresado en una cultura cada vez más reducida, asfixiada por contextos alienantes provocados por el control mediático que introyecta a la conciencia e impone una dinámica mercantil, instrumental, cosificante, de un sistema social político y económico sin participación/control ciudadano, fortalecido por un neoliberalismo ciego, que acentúa y exacerba más individualismo en sus manifestaciones, fomentando itinerarios de vida capturados por espirales de consumo, que dificultan redes vinculares. La educación pública ha sido fagocitada por las leyes de mercado y con ello hemos perdido la única posibilidad de construir "lo común” en un espacio público que nos reúna a todos y todas en equidad de derechos y deberes. Desde esta perspectiva, surgen los cuestionamientos que sostienen este "tejido problemático" que mira a la escuela como nicho de construcción de identidadalteridad para conformar lo "común” que motivaron este proyecto de investigación

\section{Identidad:}

Al buscar documentos en la red con la palabra "identidad", aparecen casi treinta millones de resultados (29.272.000), clasificados según cuadro que se adjunta: 


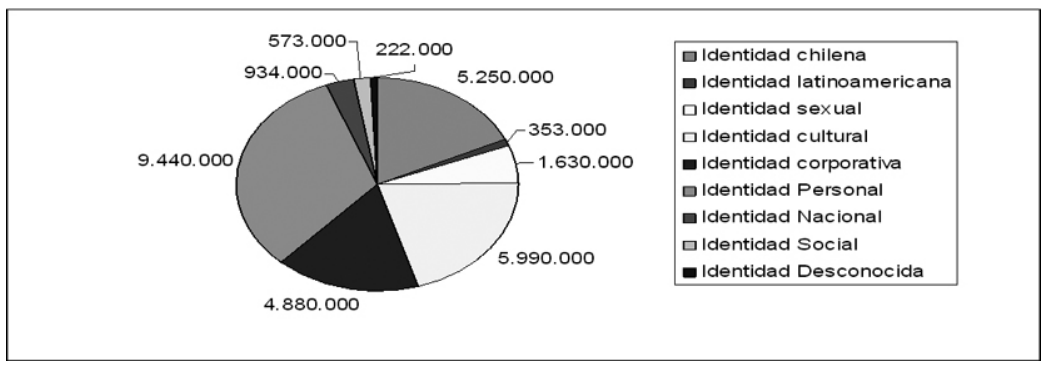

Sumado a la gran variedad bibliográfica que atañen al concepto de identidad en libros ISBN, que se han publicado en estas últimas cinco décadas, sin duda, evidencian lo recurrente de la temática y la producción de teoría desde diferentes ciencias ${ }^{12}$. Por ello es necesario precisar que en esta investigación, el concepto de identidad es trabajado desde la relación entre sujeto, el espacio del yo y la identidad, conectados en el proceso de subjetivación, que permite al individuo considerarse un sí mismo dentro de un colectivo, que a su vez, también lo determina, aludiendo con ello a una mirada antropológico- social. El concepto de identidad que trabajaremos no se comprende, como fin o como destino, debido a que no es un punto de llegada, sino una constante transformación, que la alteridad permite reelaborar constantemente, especialmente en la otredad que alude a la diferencia y no a una alteridad especular.

¿Qué es la identidad? ¿Qué significa identidad étnica, de género, cultural, humana? ¿Tenemos una identidad como especie humana? ¿En los contextos de globalización cultural en la que estamos inmersos, cuál es nuestra identidad multicultural? ¿Qué tenemos en común y qué nos diferencia?, La palabra griega, omós, que los romanos tradujeron por homo, el "hombre”, el ser humano, significa "semejante”, “igual”, “común”, “el mismo” (Jáuregui: 2001). Distinguiremos el concepto de identidad personal, aquella que se construye desde la hibridación del tejido de identidades colectivas ${ }^{13}$, desde un enfoque socio-antropológico más que psicológico, sin entrar en pugna dualista con ambas corrientes. Sin embargo es necesario precisar que la identidad personal del sujeto, pertenece al espacio del "yo", que es disciplinariamente el espacio de la psicología. "Yo" es el acto de ocupación del sitio biográfico o egocéntrico. En psicología, el sujeto es el sujeto de "sí mismo". Decir que el sujeto es el espacio del "yo" implica concebir al "yo" como principio de identidad del sujeto. En el "yo" radicaría la invariancia del sujeto más allá de las dimensiones morfológicas y psicológicas. Desde la psicología, el "yo" es el centro del estudio, su foco de atención, entendiendo al contexto, el medio, los “otros/as" como aspectos constitutivos de ese yo, que es lo central y lo medular de un sujeto individual, singular.

La antropología centra la noción de sujeto en la "interacción” que emerge del colectivo, dirigiendo la mirada a la dimensión social y no al 
espacio egocéntrico. También explicaremos la identidad desde la dimensión histórica del sujeto, como un conjunto de identidades tejidas con distintos niveles de conciencia, incorporado unas y apartando otras: la identidad femenina, la identidad masculina, la identidad popular, cultural, sanguínea, tribal, de minorías étnicas, en fin, identidades con mayores o menores rangos de "status" en la tela del "sí mismo", en desventaja con el "prototipo" configurado desde la elite ilustrada y política como sujeto histórico único.

En general en las ciencias sociales la noción de sujeto se focaliza en lo colectivo y no incorpora la dimensión del sujeto que proviene del espacio egocéntrico por considerar esta dimensión esencialista. En este trabajo se considerará al sujeto en su doble vertiente, singular y colectiva (Subercaseaux; 2002). Podríamos asumir que la dimensión intra-personal e interpersonal tejen un "yo" desde un contexto socio-histórico que lo explica, su dimensión singular, con su dimensión colectiva, su ámbito privado con el público, sus sitios de poder y/o exclusión que lo determinan junto a la complejidad de emociones y plataforma física-biológica en la que se asientan. Este tejido complejo construye muchos “yoes”, que implican un llegar a ser distinto en cada sujeto pero igual en colectivos que comparten códigos culturales comunes. (Op Cit).

El concepto de identidad que trabajaremos pretende profundizar su configuración desde la pertenencia al grupo y reconocimiento del mismo, en el que se dan relaciones de dominación y sumisión, con base muchas veces de actuaciones afectivas ante la legitimación o consolidación de la identidad colectiva con la identidad personal. Desde esta perspectiva, pretendemos iluminar esta relación social/personal, desde los análisis postestructuralistas (Foucault 1990) ${ }^{14}$ y postcoloniales ${ }^{15}$, específicamente en los estudios de campo de estrategias de resistencia y acomodación al poder oficial, con los conceptos trabajados por Bhabha de: ambivalencia, estereotipo, mimetismo e hibridación, que están atravesadas metafóricamente por una especie de "colonización" en la que existe un sujeto de poder, que debe absorber a otro sujeto a la cultura hegemónica. "el análisis de la identidad colonial que emerge de la difícil relación entre el colonizador y el colonizado y el de la condición violenta y neurótica de esa identidad, totalmente alejada de las aspiraciones civilizadoras de los gobiernos coloniales, de los misioneros cristianos o de las sociedades filantrópicas.” (Bhabha, en Vega; 2007). Esta línea de pensamiento es complementada con la teoría de los subalternos desarrollada por Spivak (2009; 2010) que complementa con los sustentos provenientes del feminismo y marxismo a la teoría postcolonial. Aunque Spivack ( 2010) critica la teoría de Foucault y Deleutze, por incompleta al no incorporar la condición psicoanalítica-social, de género a la identidad de los subalternos, hemos utilizado estos autores por que integran muy bien las fibras de la construcción subjetiva desde el psicoanálisis social, la filosofía postestructuralista, de la de-construcción, que explican a un sujeto que se configura ambivalentemente con distintos estereotipos que giran en torno a las relaciones de dominación versus sumisión. 
Desde otros análisis teóricos, también incorporamos los análisis sociológicos que hace Bauman (2006) de la identidad en la modernidad líquida, como elementos constitutivos de una identidad entendida como destino, una identidad constreñida por lo temporal, abierta y plural en que coincidiendo con Amartya Sen (2007) se comprende como un conjunto de identidades que transitan por caminos de flexibilidad acomodaticios según los contextos, carente de consecuencias vinculares estables en el tiempo. Lo interesante en la teoría de Bauman, es el traslado de la responsabilidad social en la configuración de la identidad, al individuo, que arraigado sólo en "sí mismo" ha desaprendido la dependencia afectiva, laboral, geográfica por la inestabilidad (licuación) que provoca el contexto actual. Según estas reflexiones teóricas, la crisis social se vive como crisis individual, lo que conlleva a una regresión psicologicista para comprender los fenómenos socio-personales. Por otra parte, esta identidad "líquida" trabajada por Bauman, tienen plena coincidencia con Richard Sennett, con respecto a cómo el contexto neoliberal capitalista impacta en la configuración identitaria, (Sennett:2006) ${ }^{16}$, en la que las formas de "vivir" el trabajo, desde la variabilidad, incertidumbre del mismo con su consecuente inestabilidad, exigen "flexibilidad", apertura y adaptación al cambio, disfrazando las cadenas en las cuales los sujetos envueltos por un capitalismo opresor, “creen ser muy libres” depositando los vaivenes del trabajo en la responsabilidad individual. Siguiendo a Sennett en esta problemática cabe preguntarse: “... ¿Cómo pueden perseguirse objetivos a largo plazo en una sociedad a corto plazo? ¿Cómo sostener relaciones sociales duraderas? ¿Cómo puede un ser humano desarrollar un relato de su identidad e historia vital en una sociedad compuesta de episodios y fragmentos? Las condiciones de la nueva economía se alimentan de una experiencia que va a la deriva en el tiempo, de un lugar a otro lugar, de un empleo otro." (Sennett: 2006: 28). Este traspaso de los fracasos de la vida (estabilidad, logro) desde lo social a lo personal, transita por todos los eslabones de edad y por casi todas las instituciones, atrapados en una afirmación de valores como aseveraciones estáticas y dejando la experiencia en el olvido: "Rico afirma los valores intemporales que caracterizan a la persona que él es, para siempre y de una manera permanente y esencial. Su voluntad se ha vuelto estática; está atrapado en la mera afirmación de los valores. Lo que falta entre los polos opuestos -experiencia a la deriva y aseveración estática- es un relato que organice su conducta ${ }^{17}$. (Op Cit: pág. 29). Este relato que se precisa para organizar ya no sólo nuestra conducta sino la configuración de nuestra identidad, se requiere una mediación explícita de la escuela comprometida socialmente, para colaborar con una relectura de un mundo fagocitado por el capitalismo, que ha hecho del consumo la condición de ciudadano/a, con el peso de experiencias cotidianas traducidas en "sentir" "pensar" y "actuar" que no deciden, no son, no valen, no tiene identidad.

"Por último, la construcción del Sujeto no culmina nunca en la organización de un espacio psicológico, social y cultural perfectamente protegido. El apartamento de la mercancía y la comunidad nunca se termina; el espacio de la libertad es constantemente invadido y el Suje- 
to se constituye tanto por lo que rechaza como por lo que afirma. Nunca es amo de sí mismo y de su medio, y siempre hace alianzas... contra los poderes establecidos, con el erotismo que invierte los códigos sociales y con una figura sobrehumana, divina, de sí mismo. Quienes redujeron al ser humano a lo que hace lo encerraron en la dependencia con respecto a la técnica, las empresas y los estados...” (Touraine, 1999; 71) Touraine por su parte, también realiza un recorrido interesante en torno a la construcción de sujeto, ya que por un lado alude al "muerte del sujeto" cuando lo construye desde lo colectivo, sin embargo, por otra parte, lo ubica como bandera de salvación al concebirlo como individuo. Alejada de las corrientes liberalistas y comunitaristas ubica al "yo-sujeto" como la única respuesta a la independencia para construir una sociedad alejada de estas dos dimensiones "totalitaristas", comunitaristas o liberalistas que lo fagocitan. "Yo no defino el Sujeto en términos universalistas y por tanto no sociales (criatura de Dios hecha a su imagen, portador de un derecho natural, ciudadano de una ciudad que se basa en un contrato social y por ende en el imperio de la ley), sino en términos de combinación de una actividad racional y una identidad cultural y personal." (Touraine 1998: 178). Sin embargo, aunque no permitamos el totalitarismo comunitarista y menos su fundamentalismo, esta claro que el sujeto se convierte en "ser humano" o posee identidad humana, sólo desde la interacción con lo social. "El individuo está ubicado en espacios sociales de composición relacional, los cuales "generan" una suma de fuerzas que modelan su conducta” (Matuccelli: 2007:13) al hablar del individuo social, hablamos de un individuo que desde que nace se constituye como tal desde los otros/as y es percibido como el fruto de entrecruzamientos de fuerzas que actúan en función de la estructura de relaciones sociales en acción. (Op. Cit). Lo más básico de la identidad humana, incluso en sus dimensiones biológicas e instintivas (postura bípeda, lenguaje simbólico) sólo se logran en la interrelación con otro/a humano, vale decir, es la alteridad lo que confiere identidad en las diferentes dimensiones de los humano.

\section{Epistemología en la que sea sienta el estudio}

La metodología utilizada en esta investigación emerge desde un paradigma epistemológico cualitativo, que quiere conocer y comprender las representaciones simbólicas que configuran la identidad y alteridad para conformar el sentido de lo común de los sujetos a través de sus discursos y acciones, en el espacio escolar. Desde este objetivo hemos utilizar un diseño metodológico de estudio de caso múltiple, en la medida que "son particularmente apropiados para estudiar una situación en intensidad en un período de tiempo", facilitando la identificación de los distintos procesos interactivos que conforman una realidad (Del Rincón y Latorre, 1992). Los criterios de selección de las escuelas como "casos de estudio" son: Nivel socio económico: determinados por la administración corporativa educacional del país en: colegios públicos que concentran a una población tendiente de clase baja; colegios subvencionados que concentran una población de clase media y media-baja y colegios particulares pagados que 
concentran clases medias y medias-altas. Además se seleccionaron escuelas del Contexto urbano y contexto geográfico rural, en un total de ocho escuelas.

\section{Presentación Resultados Investigación}

Los resultados se corresponden a los procesos analíticos producto de la información recogida en los registros de observación, los análisis de los documentos y el análisis de los discursos, tanto de entrevistas clásicas y formales como espontáneas y “fotos-memoria” que fueron especialmente utilizados para los niños y niñas más pequeños. Es importante señalar que la mirada se focalizó en las interacciones de los niños y niñas, con sus pares y docentes en la institución escolar, no como cultura del currículum con toda su complejidad y múltiples elementos, sino focalizada en las relaciones a sí mismo, al espacio físico, la normatividad, el sentido de pertenencia y la red vincular entre pares y docentes. Las categorías emergen desde estos diferentes ámbitos de focos de atención y recogida de información: Formas de relación con los docentes (aula); Formas de relación con la escuela (espacio físico y sentido de pertenencia); Formas de relación entre pares. Estos diferentes ámbitos relacionales, configuran una categorización que se traduce en el siguiente cuadro:

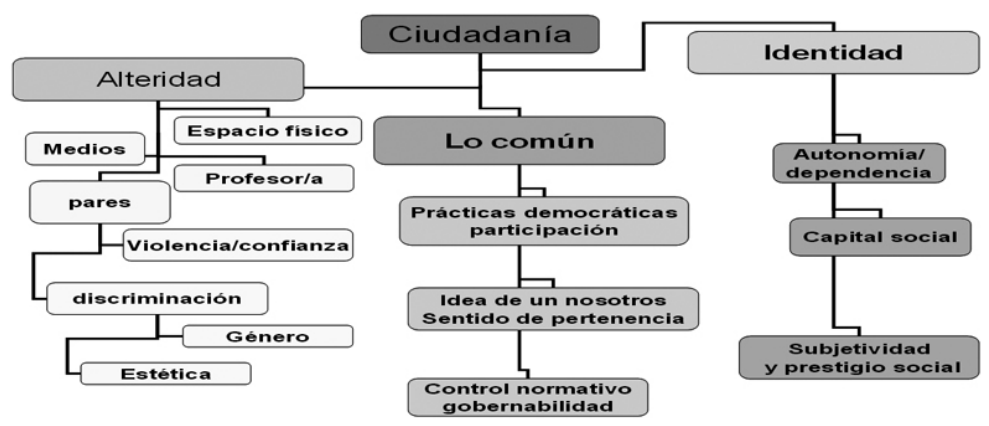

La primera matriz categorial de identidad/alteridad, reúne la información recogida con respecto a las relaciones que configura el sujeto, con el "otro/a” o lo otro, la alteridad está relacionada con aspectos de sociabilidad y modelamiento en el aprendizaje de conductas prototípicas, que subyace a la red vincular con los pares, la escuela, los docentes, los medios, y el impacto de esta relaciones en la configuración identitaria del sujeto. Estos estereotipos configurados por el poder hegemónico, se instalan en la escuela basadas en referentes de ética; estética y género: Buen o buena alumno/a; esta categoría surge de la interacción entre docente y estudiantes, y está construida por discursos y actuaciones del docente vinculada a un conjuntos de conductas “esperadas”. Estas conductas esperadas se rela- 
cionan con obediencia al poder oficial traducida en cumplimiento de las tareas, sumisión al poder y al orden establecido, acato de la normativa y logro académico. El estudiante que cumple con estas características goza de reconocimiento por parte docente y de prestigio social por parte de los pares. El mal estudiante sería la oposición a lo descrito, vale decir su polo contrario. Lo bello y lo feo, lo estéticamente "aceptado" por la gran mayoría de los estudiantes. En esta categoría los pares se excluyen y se aceptan o rechazan según un "patrón” de estética relacionada con el cuerpo o fenotipo.

Mujer y varón: prejuicios sexistas con respecto a estereotipos de lo que la mujer y varón deben hacer y pueden hacer, referidos a juegos, comportamientos y liderazgos. Esta gama de rótulos y patrones instalados en las formas de relación espontáneas en espacios de juego y recreo, se observa como exclusión y/o integración por una parte y sumisión/dominación por otra.

\section{Configuración del buen alumno, buena alumna: "La homogeneidad como valor y la obediencia ciega como coronación de ese valor”}

La forma de relacionarse en la escuela ${ }^{18}$ están instaladas en una estructura "panóptica"19 , tanto físicas (edilicias) como humanas (personales/ sociales). La organización del tiempo, los contenidos, las actividades y tareas escolares son reproducidos en la mecánica disciplinaria de control, desde la homegenidad: "todas por igual, al mismo tiempo, ritmo y espacio”. Estas formas reproducidas por las instituciones sociales, fortalecidas en una epistemología positivista, tiñen a las instituciones educativas estudiadas, a las que subyace la "verdad absoluta o incuestionable de la medición y generalizaciones" arropando a la institucionalidad con estereotipos y normativas que regulan la conducta de los que participan en ella. La cultura dominante se impone con el supuesto que somos iguales y por tanto que tenemos las mismas necesidades. En la escuela acontecen múltiples sucesos en los que se evidencia la lógica panóptica en sus rutinas: las filas para entrar y salir de la sala, los momentos informativos de patio, en los que, en una lugar "más alto", se ubica el "inspector/a” y la directiva, registrando a los estudiantes que se mueven, conversan o se salen de la fila con la respectiva sanción. Por otra parte se generalizan normativas desde lo arbitrario, como por ejemplo: Un niño se accidenta en una salida a terreno y luego en consejo de docentes se acuerda suprimir todas las salidas a terreno. Un niño se accidenta jugando fútbol y luego se suprime el juego de fútbol en la escuela, aspecto reclamado por los estudiantes, sin lograr ser escuchados. La vida y los sucesos escolares, no se miran como una particularidad compleja, se norma desde una generalización simplista, que obedece más a una lógica transductiva ${ }^{20}$ que deductiva o inductiva. El sujeto, los hechos, la vida, los acontecimientos, los conflictos, los accidentes en la escuela se invisibilizan en una mecánica de "no-pensamiento", desdibujados 
por la normativa controladora “sin sentido” y muy alejada de la vida. En más de 120 registros de observación, la mayoría de éstos, son referidos al tema de imposición de normas "sin sentido" de coherencia y racionalidad y casi la totalidad en la dinámica de autoritarismo. Se observa en la relación profesor/a estudiante, una tendencia de relación asimétrica, mediatizada por un poder y control ejercido por el adulto, quien ordena y hace cumplir estas normas ( que muchas veces él o ella mismo/a no cumplen), especialmente las que dicen relación con un "orden” preestablecido por la Institución.

Re-configurando a este sujeto niño/niña, capturado por la mecánica normativa sin sentido, que no piensa "la vida”, no discute (argumenta) los sucesos que emergen en la cotidianidad de la escuela, y menos dialoga, va construyendo una subjetividad inmersa en una pasividad de decisiones. Esta “dependencia” al locus de control externo conecta muy bien con la lógica del mercado, el que se apodera de lo social (y por ende lo personal) en la denominada por Giddens “modernidad tardía”, o por Beck, segunda modernidad; también llamada por Augé sobre-modernidad y por último en un concepto metafórico preciso; modernidad líquida acuñado por Bauman $^{21}$. Estas denominaciones que poseen un profundo análisis sociológico y antropológico, caracterizan el cambio epocal como una crisis o "nebulosa" de sentido ante los grandes cambios identificados como desarrollo y progreso, en el que hoy se evidencian profundas contradicciones y vacíos en lo epistemológico, lo social, lo económico (productivo) y especialmente lo político en los ideales que configuraron al Estado-nación. Algunas de las características sociales de este contexto se observan reflejadas en la transitoriedad de los vínculos, la fragmentación y el carácter episódico de la vida, con la respectiva ansiedad, incertidumbre, inseguridad que conlleva a la ausencia de responsabilidades. Esta percepción del sujeto consigo mismo, que se subsume a los vaivenes líquidos del éxito, carente de plataformas sólidas de redes vinculares, se encuentra en contextos que no lo reconocen, no le respetan, ni siquiera le "ven”, gobernados por una lógica de consumo y mercado sin control que desplomó al estado benefactor. Los desafíos de la persona moderna por aceptar relaciones a corto plazo, desarrollar habilidades para lo cambiante y saber desprenderse del pasado (Sennett 2008; 2006), requieren trabajar en la escuela el fortalecimiento de la dignidad entendida como libertad que implica la auto-gobernabilidad, autonomía y sentido de bien común (lo político), cuestiones que no se anidan en la cotidianidad natural y espontánea del espacio escolar.

En el horario de recreo, estudiantes asumen protagonismos según sean los mecanismos de prestigio social y pertenencia, inspirados por los mass media que le ofrecen estereotipos sociales, especialmente instalados en programas televisivos de farándula ${ }^{22}$, en las que “tragan” modelos y pautas de comportamiento sin decidir, reflexionar, actuar y forjarse como sujetos constructores de lo social y por ende personal. Luego como jóvenes que dedican gran tiempo a la comunicación online "Los jóvenes- aprendices se implican en ciclos de creación y consumo como parte de su participación en las culturas web, desarrollando simultáneamente su 
identidad online, se inventarán identidades en la Web e interactuarán con un medio que les facilita el anonimato y la fantasía por configurar identidades que anhelan. La gente joven experimenta con diferentes identidades online a través de la escritura de narrativas (fan-fiction), representaciones multimedias de ideas, uso de diferentes herramientas digitales de comunicación, adopción de roles e inmersión en mundos virtuales. Actualmente los jóvenes prueban sus identidades a través de su presentación en páginas Web, blogs, y redes sociales”. ${ }^{23}$.

Paradójicamente, al maestro/a inmerso en el espacio artificial de la "sala de clases" sólo le interesa que su estudiantes se comporten de forma obediente, y aprendan la lección para obtener buenas "mediciones estandarizadas", no se observa intencionalidad por construir un sujeto ciudadano a contrapeso del sujeto-consumidor, un hombre y mujer que posea un relato biográfico ético y político con identidad personal, denso en redes vinculares, como sostén a los vaivenes de navegación en esta líquida modernidad.

\section{Trato dado al otro/a: pares y convivencia: El mal trato}

A lo largo de la investigación se pudo constatar que dentro de los centros educativos la dinámica frente a este tema es la siguiente: los niños y niñas que se encuentran en grupos pequeños de amigos cercanos son muy leales entre ellos, dándose una dinámica de compañerismo recíproco, pero en grupos más numerosos, donde las relaciones no se dan desde la cercanía y los afectos, los niños acostumbran a manifestar bajos niveles de tolerancia y frente a cualquier rose con sus pares, las reacciones más comunes se expresan desde las descalificaciones e insultos, hasta los golpes. Esto se da más comúnmente en los cursos superiores (de $3^{\circ}, 4^{\circ}$ y $5^{\circ}$ Básico). Se puede evidenciar en los siguientes extractos:

Niño 1: Profe, ¿Hay que escribirlo?

Niño 2: No, tonto estúpido. ${ }^{24}$

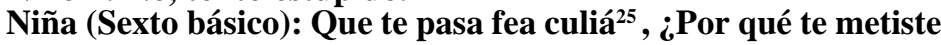
en esa wea? Hocicona.

(Le tira el pelo a la niña de cuarto y viceversa)

Niña: ii¡suéltame, suéltame!!!

Profesor: Mírenlas y eso que son primas. ${ }^{26}$

El mal trato, genera una plataforma relacional en que los niños y niñas desarrollan su identidad a través de lo que los otros/as, les permiten ver de ellos (espejo), en este sentido se puede ver que en los registros existen focos de exceso de poder de parte de algunos niños/as hacia otros que se muestran más débiles y sumisos frente a esto. Este mal trato emerge traducido en descalificaciones, exclusiones, agresiones verbales o físicas. Sin embargo no se puede asociar el uso de palabras groseras únicamente a mal trato o descalificación, pues en los múltiples registros de observación, las palabras soeces se utilizan en contextos de amistad y cariño, como lo expresa la cita: 
Niño: “Oye, el otro día puta que te veíai bonita”.

Niña: ¿Cuaaaaaaal?,

Niño: “Aaaaa, el otro día cuando te vi pasar por ahí po”. Niña “ ¿El domingo?” siiiiiiiiiiii. ${ }^{27}$

Ello refleja como estrategia de trasgresión en los niños y niñas, la leve importancia que otorgan al lenguaje como forma o significante y el enorme peso que atribuyen al mismo, como realidad de significado. Vale decir, es el contexto el que sitúa al habla con su "sentido" de comunicación y no el habla por el habla misma, perdiendo su valor de uso. El peso, lo da el contexto y el lenguaje mudo es lo que subyace a las emociones y relaciones en sus significados. Ello denota cierta ausencia de racionalidad y coherencia (forma-fondo) en la forma de relación vincular y con-vivencia.

En la dinámica de la cotidianidad de la escuela, se observan episodios que de tanto repetirse se vuelven "normales", como es el caso de un pequeño quemado que se siente mal tratado por sus compañeros al escuchar las burlas debido a su condición física. El problema grave de este suceso, es que la acción agresora se invisibiliza, lo anormal se vuelve "normal" y los docentes hacen como "si nada pasa" ante el cansancio por la repetición de estas conductas. Ello refleja una pérdida del sujeto en la configuración de su dignidad, su respeto en la vida cotidiana de la escuela, en la que se supone se forja su identidad y su sentido ciudadano.

\section{Discriminación por estética}

En los distintos casos encontramos que los niños discriminan a los que no cumplen con las características socialmente atribuidas a la belleza. Muchas veces los niños y niñas se dejan influenciar por los prototipos de belleza entregados tanto por la televisión como también por la escuela, la familia y la sociedad en general, los cuales en la mayoría de las ocasiones no coinciden con las características del pueblo chileno. Ésta es una problemática que afecta la red vincular y sentido de identidad, al discriminar a una persona por su aspecto físico o fenotípico, vulnerando sus derechos de ciudadano, básicos de un común unidad. El ser diferente a los demás no nos hace menos ciudadanos, el ser más bajo, más gordo, más moreno, el tener un corte de pelo que no está a la moda, no debiera traducirse en el terreno afectivo y ético-normativo como "ser más" o "ser menos" que otros, que amerite la exclusión a lo común...Pues al parecer lo común en cuanto a representación simbólica observada, lo ha configurado el mercado canalizado por los mass media.

Alumno: Oye Angélica, mejor ándate pa la última fila Alumna: ¿Por qué po' si la profe me puso acá? Alumno: Porque con tu cara de poto ${ }^{28}$, tení que estar atrás (ríe) ${ }^{29}$

De más de un centenar de registros de observación, más de una decena de planillas de observación están referidas a discriminación por esté- 
tica y belleza. Durante la recogida de datos todos los registros relacionados con estética y belleza, siguen esta dinámica de descalificación y de desvaloración que se arropa de características físicas que concuerdan con el patrón de belleza validado por el poder dominante, y que se corresponde al fenotipo aria, hombre/mujer.

Entrevistadora: Ahora dime ¿cuál es el lugar que menos te gusta de la escuela?

Niña: Mmm..., el lugar que menos me gusta...la cancha de cemento

Entrevistadora: ¿Por qué?

Niña: Porque ahí... mmm...... andan todos los niños de mi curso y me molestan

Entrevistadora: ¿Qué te dicen?

Niña: Ehhh me empiezan a decir que soy negra y gorda y me empiezan a molestar. Me dicen negra $\mathrm{si}^{30}$

\section{Discriminación por Género}

El concepto de género es un concepto aprendido y construido por cada sociedad para sus varones y mujeres. Esta construcción comienza en las familias y el hogar desde el momento en el que el niño/a nace, e incluso antes, pero se agudiza principalmente en las escuelas, donde niños y niñas comparten la mayor parte del tiempo. En este lugar los niños se identifican como varones y las niñas como mujeres diferenciados por su plataforma biológica en primer lugar, y en segundo lugar sumándole, aspectos culturales respectos de las acciones aceptadas por el grupo, en lo que "debe" realizar cada uno. En los centros educativos investigados se encontró gran cantidad de registros referidos a este tema, justificando la violencia física en varones y privilegios de liderazgo como mecanismos de discriminación.

En el caso de estudio del colegio privado, confesional y particular pagado, la discriminación de género se expresa exigiéndole a la "niña" comportarse según la imagen de mujer cristiana con rasgos tales como: paciente, serena, sacrificada, "señorita”, dispuesta a soportar, renunciar y ceder. Vale decir, la discriminación de violencia es disfrazada por la represión, la renuncia, la tolerancia, la paciencia y el autocontrol. Contradictoriamente según las cifras, las mujeres cada vez están tomando más participación en la administración de los hogares y en los puestos de trabajos, cuestión que no se integra al currículum.

"Las niñas deben hacer cosas femeninas como maquillarse, hacer pijamadas y jugar a las muñecas, mientras con los hombres deben hacer cosas masculina como jugar fútbol, a la pelea y a las figuras de acción.”

Entrevistadora: $Y_{¿}$ Qué crees tú que pueden hacer los niños que no pueden hacer las niñas?

Niño: Pelear ${ }^{31}$ 
En este discurso, queda claro cómo los niños y niñas diferencian ciertas acciones e incluso ciertos juegos en "para hombre" o "para mujeres" marginando a unos de los otros, haciendo que niños y niñas crezcan con sentimientos de represiones respecto a la imposición que no "pueden" jugar a ciertos juegos ya que socialmente está establecido lo contrario. Por otra parte, el levantamiento de esta categoría se ve justificado por otra respuesta obtenida de la misma entrevista anterior en una pregunta referida al respeto entre los compañeros/as dentro de la escuela. La niña señala al respecto que: "Niña: Los hombres se pueden defender a golpe, las mujeres no, porque no pelean". ${ }^{32}$

En esta respuesta se observa otro tipo de discriminación en que el varón puede defenderse a golpes, legitimando la violencia física, mientras que ellas no pueden, sólo porque son mujeres. Llama la atención esta respuesta ya que al ocurrir situaciones así dentro de la escuela, las niñas y los niños legitimarán el valor de la violencia en el varón y en las mujeres se anulará, en la lógica de la "tolerancia” la aceptación de dichas conductas por el hecho de ser varón. Los niños buscarán ser respetados mediante golpes mientras que las niñas tendrán que hacerlo de otra manera. Esto es, visiblemente un factor que afecta al ciudadano/a en su forma futura de hacer valer sus derechos o deberes. En base a esto, no debiera causar asombro el enterarse de las cifras de maltrato hacia la mujer que existen en el país. "El $50 \%$ de las mujeres en Chile dice haber sido víctima de violencia doméstica... En lo que va corrido de este año, la cifra de femicidios llega a 56. En 2007, fueron 58. Es decir, los esfuerzos no alcanzan todavía a cambiar radicalmente el escenario. "Muchas de las situaciones de violencia se dan porque hay muchas personas que creen que esto es normal. Es un problema cultura”, asegura Albornoz.” (BADE, G; 2008) Así la vivencia de ciudadanía en la escuela requiere de una mirada reflexiva y práctica de: ciudadanía y educación como lo desarrolla Arnot (2009) en la que distingue distintas formas de ciudadanía según género.

\section{Participación, Democracia y Control Normativo}

Esta categoría surge con los registros de observación intra-aula, entrevistas y algunos análisis de documentos. En dos escuelas públicas y en la escuela rural de la región, se observa una construcción de consenso ante las normas que ordenarán la convivencia de la escuela, destacando que en la escuela pública urbana, esto se enfatiza en el sector parvulario y tiende a desaparecer, paradójicamente, a medida que avanza el tramo evolutivo escolar. Sin embargo, en los cinco casos restantes, los estudiantes no deciden casi nada, ni el turno de habla, lugares de asiento, contenidos, actividades, espacio, tiempo escolar. En siete de los casos observados, la directiva es escogida por el docente, ante el estereotipo configurado de "buen alumno o buena alumna”. En dos casos, el docente escoge una terna, y los niños y niñas eligen ante esta propuesta a sus líderes. Vale decir, la participación es parcial, sesgada y la democracia deliberativa es arbitraria según valoraciones del docente ante su evaluación de "buen alumna o buena alumna", a lo 
que subyace una forma de mirar al niño y niña como sujetos carentes de derechos por su condición de tal.

Se evidencia control normativo para todos los niveles y elementos del currículum: horarios, normas de patio, uniformes, orden, aseo, deberes académicos, deberes de apoderados, formas de presentación personal, que además se encuentran consignados en los “estatutos de la institución”. Llama la atención que en su mayoría, los deberes se concentran en los estudiantes y apoderados, escasamente en los maestros/maestras y directivos/ as. El docente es el agente regulador de normas dentro de la sala, en la que prescriben los ejes sustantivos éticos de lo "correcto" e "incorrecto", que en su mayoría no tiene sentido para los niños y niñas y por supuesto sin participación en su creación y consenso. El libro de clases, es el receptáculo de la sanción del trasgresor, muchas veces depósito de la emoción negativa del docente al perder el control disciplinario y del orden establecido. La tendencia de las anotaciones en el libro de clases de $1^{\circ}$ a $8^{\circ}$ básico, es de un $90 \%$ de anotaciones negativas y un 10\% de positivas. El análisis de los textos, reúne líneas discursivas que transitan por la “desesperación” del docente ante la pérdida de su poder de control, sin evidencia posterior que la real problemática ha sido abordada y trabajada con los trasgresores. Sólo se canaliza al poder superior para acentuar la sanción.

En los recreos se generan contextos en los cuales se observa libertad para agruparse, seleccionar los juegos compartidos y actividades diversas. Ante la pregunta a los estudiantes respecto si el establecimiento presenta contextos y situaciones en las cuales el estudiante puede elegir, ellos responden que no, y que sólo es posible hacerlo en el recreo;

\section{“a veces nos anotan por llegar atrasados, porque una vez nos anotaron porque llegamos tarde a gimnasia con un compañero, y la tía no nos dejo entrar, y tuvimos que ir donde el tío Gustavo para que nos diera un pase y llegamos y la tía nos anotó porque habíamos llegado diez minutos tarde, y habíamos llegado un minuto tarde". 33}

En general en todos los casos, que suman ocho escuelas, el cumplimiento de normas como plataforma común, se percibe como un sin sentido por los estudiantes. Éstas son vivenciadas como una contradicción con el sentido común, sustentado en razonamientos que emergen de las lógicas reflexivas de niños y niñas. Ello debilita la seguridad en sus reflexiones individuales y colectivas, sus posibilidades argumentativas, sus sentidos de pertenencia como actores y protagonistas (ciudadanos), domesticándolos a obedecer ciegamente como dispositivo de subsistencia o sobre vivencia, en la mal llamada “común-unidad” escolar.

Se puede decir que el control normativo en sus múltiples formas tiende a debilitar el sentido de pertenencia en los grupos estudiados, pese a la rica actividad social que se propicia en el establecimiento. Se observa una subjetividad que demanda espacios de expresión y que es silenciada 
por las pautas de acción que desarrollan los docentes desde una aproximación maternal/paternal, mediatizada por el afecto “controlador” y coercitivo que es reforzada por la familia, con lo que se identifican algunos centros.

Los dispositivos ${ }^{34}$ de control actúan fortaleciendo dicha experiencia a través de la libreta de comunicaciones asociada a la información de referencia negativa y castigo de los padres; el uso de diseminación del control involucrando a los propios compañeros, aquellos que forman parte de la convivencia grata, quienes se transforman en controladores (reproductores) efectivos de las tareas, se presentan como "deberes ser" de responsabilidad ante el grupo, que suma al control del profesor y el inspector, llegando hasta mensajes-“carteles” sensibilizadores, personalizando en listas públicas de buena conducta y mala conducta para mantener el orden dispuesto en las sala de clases.

\section{Prestigio social}

Esta categoría se levanta con diferentes significados según la dependencia administrativa de los centros: En el colegio particular pagado y subvencionados, ambos confesionales, la categoría de prestigio social se configura desde la "identificación" de un estereotipo vinculado a la excelencia académica, obediencia al docente, cumplimiento de normas y buen trato a compañeros/compañeras. Este patrón y su vivencia, permiten al sujeto gozar de “prestigio social”. Esta categoría presenta una evolución desde $1^{\circ}$ nivel de transición al $4^{\circ}$ básico, en la que se distinguen matices en los comportamientos por sexo y a medida que avanzan en el tramo evolutivo, se adhieren a este patrón normas y valores morales, tales como solidaridad, respeto a Dios, normas y deberes, los cuales son seguidos y difundidos por los líderes que sirven de ejemplo para los demás niños del grupo. Sin embargo este comportamiento moral de base religiosa, no se mantiene en cuarto año básico, primando un liderazgo que se ordena según los niños que representan los mayores intereses del grupo curso, de acuerdo a los intereses y comportamientos comunes.

En los colegios municipales, públicos el prestigio social lo configura el patrón o estereotipo de "resistencia” y trasgresión al poder oficial. Vale decir, el que goza de prestigio social en su grupo de pares, es el que se rebela a la norma, el más violento, el que se atreve en valentía romper el mandato oficial. Esta legitimidad que hace el grupo a su líder, se da por grados según tramo evolutivo, crece en la medida que se avanza de nivel en el tramo de primaria.

Si bien, en todos los centros la categoría que se configura de prestigio social, cobra mayor fuerza desde el grupo de pares a medida que avanza el ciclo evolutivo, en los colegios subvencionados y particular pagado, esta legitimación de pares, es más lenta y hasta cuarto básico hay un fuerte énfasis de prestigio social, otorgado por la configuración que hace el do- 
cente de este estereotipo apegado a la obediencia del cumplimiento de la norma establecida por el poder oficial.

También se configuran estereotipos sexistas en el prestigio social diferenciado por nivel económico. Cabe destacar que a muy temprana edad, una niña de primero básico de una escuela municipalizada goza de prestigio social por resistir todas las normas establecidas y contradecir estereotipos estéticos conservadores, a diferencia del colegio particular pagado confesional en que el prestigio social femenino, los configura la imagen de la virgen, madre abnegada, en un marco burgués femenino conservador. Esta valoración al prestigio social por los pares, podría predecir dificultades en la red de cohesión social vincular puente, pues las configuraciones obedecen a estereotipos muy disímiles en el reconocimiento del grupo de pares a quien goza de aquel prestigio en el liderazgo del grupo. Estas representaciones simbólicas de prestigio social en la infancia, son preocupantes a la hora de configurar el imaginario de un tejido social que tiene por objetivo una cohesión social puente íntergrupos.

Visto de esta forma, si los individuos no logran cohesionarse ni forjar una idea de un "nosotros”, difícilmente lograrán desarrollar valores ciudadanos, debido a que el trabajo ciudadano no es una tarea individual, sino un ejercicio social. Sin embargo, en muchas situaciones se pudieron ver dinámicas que sí aluden a esta dinámica, como por ejemplo, en juegos de patio, en dónde los niños y las niñas al estar fuera de la supervisión y autoritarismo del docente, practican valores ciudadanos correspondientes al ámbito del espacio común, como el respeto, la tolerancia, la capacidad organizativa, la solidaridad. Dadas estas dos contraposiciones, se puede concluir, que la dificultad que poseen niños y niñas para construir el concepto del "nosotros", guarda relación con la percepción que el dominio de la Escuela, no es suyo, lo albergan los docentes y, en general, los adultos en nuestra sociedad. Es por esta razón que al contestar la pregunta de “¿Sientes que el colegio es tuyo?”, muchos respondieron que no, que es de otros, o porque mandan otros, no poseen sentido de pertenencia hacia el espacio escolar por una percepción asociada al derecho y al deber participativo. De esta forma, ese “otros" correspondería a "Los adultos”, pues los niños y las niñas cuando se encuentran solos, logran cohesionarse.

Los individuos se configuran en la medida en que practican la alteridad, es decir, se relacionan con un par que les permite compararse, diferenciarse y por lo tanto, descubrirse relacionándose con otros dentro de un grupo, desarrollando el sentido social/personal. La identidad en un principio, es un proceso que ayuda a definirse individualmente, es decir, sirve para crear conciencia de la propia existencia, luego, la identidad se construye desde la colectividad, por lo tanto, las prácticas pedagógicas con sus implicancias relacionales pueden llegar a plasmar tanto desde lo negativo como de lo positivo, la construcción de lo que niños y niñas serán en el futuro como ciudadanos. 


\section{Palabras finales a modo de resultados 0 reflexiones emergentes}

Lo común y la sociedad se presentan como categorías debilitadas tanto desde la experiencia y significación de los estudiantes, (representaciones simbólicas) así como de los docentes. Ambos coinciden en sus acciones y discursos una constitución de lo social regulado por una normativa sin sentido y pertenencia, en el cual ellos actúan de forma pasiva. Se observa una forma de relación como transacción, regulada por tendencias neoliberales de sustitución de lo público por el mercado. Se instalan estereotipos y actuaciones reguladas por los medios de comunicación en general, en que los modelos a imitar por los niños y niñas, obedecen a los íconos que la "farándula" de programas televisivos valoran e instalan como legítimos, exacerbando la lógica de transacción y sustitución de la ética por la estética inventada por el mercado, careciendo en la mayoría de los casos de valor político en torno a la convivencia y el bien común. Los estudiantes, reflejan representaciones simbólicas configuradas desde los medios que aluden a: estereotipos sexistas, estereotipos estéticos, relaciones de exclusión, discriminación, inseguridad y desconfianza. En suma, se observa un déficit de lo común-social en los niños/niñas mediado por la experiencia disponible dada por la procedencia de clase social y la edad y por la mediación débil realizada por los docentes.

Las representaciones simbólicas que se configuran en torno al "prestigio social” avizoran un problema serio de fragmentación social por clase, en lo más profundo de la identidad que se valora como "prestigiosa", contradictoria según colegio de procedencia. El tema de cohesión social en sus dimensiones vincular "puente" 35 es fundamental si se quiere crecer como país en desarrollo humano y capital social. Sin embargo la estructura educacional del país posee una plataforma administrativa escolar que segrega en nichos sociales de clase, lo que implica desde los primeros años distintas configuraciones en las representaciones de lo común, la identidad, la forma de tratarse, el prestigio social, los sentidos de pertenencia y por ende el ideario común.

Las escuelas observadas en sus dimensiones funcionales y estructurales se caracterizan desde el panóptico de "vigilancia” para controlar y castigar a quién no cumpla con el orden establecido. Un orden que intenta imponer la "regularización" de la vida, que en sí misma es caótica ${ }^{36}$ a diferencia de un orden jerárquico como objeto imaginativo que organiza la auto-comprensión individual (Sennett; 2006) que también es orden militarizado adoptado por la obsesión de uniformidad de las instituciones en la modernidad. Estas escuelas capturadas en su espacio y tiempo por estas características "propias de la modernidad” está desfasada con el sujeto que interactúa en la nueva o líquida modernidad, que requiere fortalecer su identidad en términos de auto-gobernabilidad, conciencia de sí (texto y contexto), sentido ético-político (idea del bien común) con la respectiva consolidación de redes vinculares que le permitan al sujeto comprender los sucesos de la vida social desde lo social, y no desde lo individual únicamente en 
dónde la meritocracia (subyugación a la explotación, obediencia ciega a la danza del mercado) son los soportes del éxito o el fracaso de la vida.

En el contexto de estas reflexiones emergentes, producto de análisis interpretativo del discurso y la acción, se levantan nuevas preguntas e hipótesis que ameritan la necesidad por re-pensar el sentido de la Escuela, que implique mirar más allá a la mera reproducción de aprendizajes descontextualizados del mundo social-personal, político y económico. En este sentido, el foco debiera iniciarse en los docentes, administrativos y estudiantes, en donde prime, la identidad local de la común-unidad, sustentada en la solidaridad, la tolerancia, el respeto y la libertad, valores básicos para educar en democracia fortaleciendo la identidad personal.

Los docentes tienen el gran desafío y deber ético por conocer, comprender y vivir un proyecto político, como también la toma de conciencia sobre la importancia y repercusión social de la escuela en la formación ciudadana y la construcción de identidad, como base para la cohesión social de un pueblo. El tema de la homogenización, no deja de ser menor en la forma de configurar el itinerario cotidiano de escuelas muy disímiles en TODO, sin embargo a simple vista se observa un "habitus" 37 estructurante y estructurado por un "automatismo" mecanicista que arropa la escuela de horarios, normas, estatutos, reglas y especialmente mediciones estandarizadas en que lo desigual se disfraza de lo igual y por tanto perversamente y /o profundamente inequitativo como sistema social.

Se destaca la realidad rural en el caso estudiado, como espacio escolar de congruencia con la formación ciudadana y cohesión social. ¿Por qué en la ruralidad se da esta dinámica democrática? Un aspecto relevante lo constituye el trabajo de parte de los docentes y estudiantes de esta escuela rural que está centrado en la auto-gestión, vale decir, ellos son quienes buscan sus propias redes de apoyo para cambiar cuestiones curriculares y así plantear una propuesta educativa distinta dentro de un sistema apresado por la burocracia, el miedo a la sanción ante las mediciones como control. Otro aspecto sumado al compromiso docente y estudiantil, lo constituye el espacio físico, la estructuración del tiempo y las aulas tan disímiles con los centros urbanos. La naturaleza en la escuela rural, es una "otra” que interactúa desde lenguajes congruentes y armoniosos arropados por la fuerza arrolladora del ecosistema natural, lo que se traduce en distintas formas de relación y vivencia de ciudadanía y cohesión social en la escuela. Esta escuela rural, nos ha permitido volver a creer en la "escuela" a pesar de que el sistema homogenizador y aplastante del sistema educacional, muchas veces no vaya en favor (en la acción, no en el discurso) de una cultura escolar que desarrolle identidades singulares y colectivas en bien de una formación ciudadana. Nos ha devuelto la esperanza por hacer posible una "nueva escuela" que se vivencia en la silenciosa cotidianidad de unas murallas escondidas entre los árboles, un río que acompaña con su lenguaje permanente, una huerta y el colorido de las flores, el canto de los pájaros como lenguajes que se tejen junto a los lenguajes del afecto en las relaciones de docentes y estudiantes, directora y profesores/as, el compromiso, el gusto 
por la tarea, las raíces folklóricas, la integración de las familias, y la sonrisa de unos niños y niñas que no quieren marcharse de la escuela.

Es necesario terminar estas reflexiones resaltando el afecto que sienten los estudiantes hacia sus profesores, sobre todo en la primera infancia, es decir, a pesar de todos estos registros de autoritarismo docente e institucional que hemos observado en la investigación, los estudiantes manifiestan agrado por asistir a la escuela. Este sedimento de gran carga afectiva, vinculado a los pares y a los docentes, es una gran potencia para remirar la importancia de la escuela en la formación para la ciudadanía. Sin embargo no se podrá hablar de propender a una mayor cohesión social a través de la escuela, porque en Chile la escuela no es el espacio público para la convivencia de sus ciudadanos, muy por el contrario, acentúa la “cohesión vincular” intragrupo pertenecientes a nichos sociales, totalmente fragmentados entre sí, con fuertes cargas de identidades colectivas (aspecto discutido en el cuerpo de este articulo) destacando la peligrosidad en la configuración de prestigio social, de forma antagónica según clase social. El espacio escolar en nuestro país segrega y fragmenta aún más, lo que ya está segregado geográficamente, culturalmente y socialmente a través de sus dimensiones administrativas: particular pagada versus clase media y media alta, subvencionada, media y media baja y pública clase de baja o de pobreza en su mayoría. Ello plantea un desafío mayor para valorar la importancia de la escuela como potencia transformadora de realidades, confiando en la capacidad de los docentes y la institución para no perder la esperanza en construir una sociedad más justa cuyos protagonistas sean nuestros niños y niñas de la escuela y por ende la sociedad.

A la escuela le compete comprender lo público como espacio de interés colectivo. Entender la escuela como plataforma de fortalecimiento de cohesión social, ya que la fragmentación dificulta el pacto político social y provoca freno al cambio y debilita la gobernabilidad democrática, implica re-mirar la escuela como centro dinamizador de valores cívicos y conocimiento de derechos y deberes. Ello implica remirar la escuela en esta modernidad líquida ${ }^{38}$ en sus redes vinculares, fugaz en su convivencia, incierta en realidades laborales y por tanto ambivalente de identidades, más que en seguir insistiendo únicamente en los puntajes de mediciones de matemática, lectura y escritura. Sin duda herramientas básicas y sustantivas de todo ciudadano y ciudadana para ejercer sus derechos y deberes, pero que fracturadas y ajenas al contexto económico, político y social, son dispositivos de adiestramiento para la reproducción del sistema imperante. Todo ello requiere de una maestra y maestro que valoren el estudio permanente y la lectura, que anhelen instruirse en temas de filosofía política, de sociología, antropología, literatura, que permita el pensarse así mismo/a, para reconstruir lo social, la vida, la escuela, como aspectos sustantivos del deber docente, porque independiente de la disciplina particular que posea cada docente, la Educación es una institución de bien común más que bien social y como tal, todo maestro y maestra que forman parte de dicha institución, requieren saber lo que implican los conceptos de lo social y lo común, en esta era compleja, llamada nueva, tardía o líquida modernidad. 


\title{
Notas
}

\author{
${ }^{1}$ Silvia Redón Pantoja: CONICYT - Fondo Nacional de Ciencia y Tecnología República \\ de Chile FONDECYT 11070100 2007/2009: "La escuela como espacio de formación \\ ciudadana”.
}

Silvia Redón Pantoja investigadora principal; Fondo Nacional de Investigación en Educación, Ministerio de Educación República de Chile: FONIDE código 035- 2007/2008: La vivencia de "lo común” en la escuela: Prácticas y configuraciones de representación simbólica de cohesión social y construcción de comunidad en niños y niñas.

${ }^{2}$ Existen documentos históricos que permiten conocer la existencia de escuelas en Egipto del Imperio antiguo, unos 2.500 años antes de nuestra era ${ }^{2}$ (Esteve; 2003:35). José Manuel Esteve, (ver "La tercera revolución Educativa” 2003) Describe la primera revolución educativa, con la primera aparición formal de la escuela que "enseña”, situando históricamente este proceso en el antiguo Egipto, con la aparición de las primeras escuelas destinadas a la escritura "escuelas de escribas del faraón" reservadas a la elite sacerdotal. Una segunda revolución educativa la constituye la aparición de la imprenta y el traslado de lo privado (preferentemente la Iglesia y particulares) a lo público en la incipiente responsabilidad del Estado en la Educación (Prusia 1787). Finaliza su obra, desarrollando con profundidad la tercera revolución educativa, que implica la complejidad de la docencia en una escolarización que intenta ser inclusiva. El 100\% de cobertura en la escolarización, es también el 100\% de problemáticas sociales, multiculturales, éticos, morales, en un espacio escolar en el que el docente debe integrar en el aula problemas de delincuencia, abusos, atropellos, severas carencias emocionales, "sin sentidos" en un contexto socio-histórico en el que el ser humano se desdibuja cosificado por el mercado.

${ }^{3}$ Gimeno Sacristán: destaca la similitud de estructuras, significantes, ritos, habitus con el monasterio y la cultura eclesial. Ver Página 159 “ El alumno como invención”.

${ }^{4}$ Un hito importante de nuestra sociedad moderna, lo constituye la “Toma de la Bastilla” y la declaración de los Derechos Humanos en la revolución francesa el año 1789, que obliga al estado la responsabilidad y el deber por la educación de sus ciudadanos.

${ }^{5}$ Ver Gimeno Sacristán. Hace referencia pública de la escuela en Convivir en la aldea global, publicado el año 2000.

${ }^{6}$ Foucault en "Vigilar y castigar” Aborda el tema del panóptico desde su dimensión histórica, asociada a las plagas y epidemias que exigían de la localidad normativas legales de vigilancia control y castigo y lo utiliza como metáfora para explicar prácticas institucionales de regulación, normatividad y sanción.

${ }^{7}$ Bajo el lema "Gobernar es educar", Aguirre Cerda fue electo como Presidente de Chile para el período entre 1938 y 1944. Allende, Salvador, 1971-1973, fue también un gran estatista contemporáneo, que más se asemejó a Aguirre Cerda, ambos destruidos por el poder oligárquico de un estado clasista y postcolonial.

${ }^{8}$ Golpe de Estado en Chile. 11 de septiembre de 1973 liderado por el dictador: Augusto Pinochet Ugarte, muere ( se suicida) el presidente elegido democráticamente: Salvador Allende Gosen. 
${ }^{9}$ Pérez Gómez A.(1998) Ver el concepto y el cruce de 5 culturas propuesto por el autor en” la cultura escolar en la sociedad neoliberal.” Morata. Madrid.

\footnotetext{
${ }^{10} \mathrm{http}$ //www.educarchile.cl/Userfiles/P0001/File/Mineduc\%202004\%20Comisión\% 20formación\%20ciudadana.pdf ; http://www.curriculum-mineduc.cl/docs/informe/comisionciudadana.pdf
}

${ }^{11}$ Carlos Peña (2007). Crónica de “El Mercurio” sección Reportajes D12 “El mal infinito”. Domingo 10 de junio 2007.

${ }^{12}$ La sociología, la filosofía y el existencialismo, el estructuralismo, el post-estructuralismo, la hermenéutica, la psicología presente en todas sus corrientes: analíticas, conductistas, socio-constructivistas, humanísticas, antropológicas, la economía y la literatura con toda su riqueza narrativa de representaciones simbólicas.

${ }^{13}$ Amartya Sen, en su libro "Identidad y violencia” 2007, realiza un detallado itinerario del concepto de identidad desde las identidades colectivas con las luces y sombras que esto implica para el tejido social de un estado nación.

${ }^{14}$ Foucault en "tecnologías de yo" clasifica estas tecnologías en cuatro dimensiones: mecanismos de producción; sistemas de significaciones sentidos y símbolos, sistemas de poder como dominación ante fines impuestos que involucran la objetivación y el espacio del cuerpo del sujeto que decide.

${ }^{15}$ las dos obras más influyentes del psiquiatra negro FRANTZ FANON lo constituye "Peau Noire" (1952), que se presentaba en la época como un «sociodiagnóstico de la colonización», y "Les damnés de la terre” (1961), una obra política y militante, que apareció póstuma en París que apareció póstuma en París y precedida de un prólogo explosivo de Jean Paul Sartre. María José Vega Universitat Autònoma de Barcelona http://turan.uc3m.es/ uc3m/inst/LS/apolo/bhabha.html

${ }^{16}$ Sennett en la corrosión del carácter” 2006 novena edición.

${ }^{17}$ La negrilla es mía para relevar la idea.

${ }^{18} \mathrm{Al}$ referirnos en el texto al concepto de “escuela” se alude a los casos estudiados y no al concepto como generalización.

${ }^{19}$ Panóptico: De pan- y -óptico, adjetivo: Se dice del edificio o construcción cuyo interior puede verse completamente desde un punto. Diccionario, "El país". Es utilizado para graficar el dispositivo de control, vigilancia y castigo que permite "ver, sin ser visto". Tomado del filosofo Bentham que en 1791 crea la estructura de los centros penitenciarios. http:// es.wikipedia.org/wiki/Pan\%C3\%B3ptico. Así, Foucault (en Vigilar y castigar) consideró el diseño como un ejemplo de una nueva tecnología de observación que afecta al ejército, las fábricas y la educación.

${ }^{20}$ Piaget define la transductividad como una característica del pensamiento egocéntrico, en el que el niño/niña explica un hecho o característica particular, por otro hecho particular: por ejemplo: el perro es café porque tiene cola larga. LA John H. Flavell, 1997 edición revisada. Psicología evolutiva de Jean Piaget Editorial: Antonio Machado. ISBN: 9788477740872 
${ }^{21}$ Bauman alude a las denominaciones realizadas por Giddens y Beck en sus entrevistas compilada en el libro: "La Ambivalencia de la Modernidad y otras conversaciones". El concepto utilizado por Augé se encuentra en su artículo "Sobremodernidad; del mundo del hoy al mundo del mañana” en http://www.scribd.com/doc/7986929/Marc-Augesobremodernidad

${ }^{22}$ Se recogió información masiva a través de encuestas con respecto a lo que hacen niños y niñas al llegar a casa, otorgando a la TV y juegos informáticos la supremacía en la utilización del tiempo, compartida con tareas escolares y en algunos casos, el juego de barrio o vecindad. Estas características están diferenciadas por edad y por clase. En las escuelas públicas, el barrio y la calle ocupan un espacio para la recreación, en reducido porcentaje, en el caso rural, la red vincular con parientes es significativa, sin embargo se impone en todos los niños y niñas, el mayor tiempo libre, dedicado a mirar TV y juegos informáticos. Con las respuestas masivas se logró evidenciar la gran cantidad de tiempo que destinan a este medio de comunicación masivo, qué tipo de programación prefieren, etc. Los datos recogidos son de suma importancia si se considera que en nuestros tiempos la televisión tiene una gran presencia en el itinerario vital de las personas, pues configura pensamientos, provee modelos a seguir y maneja la información de lo que en el mundo acontece, por lo tanto, podría tener fuertes influencias en los significados que los niños y niñas construyen. (Maritza Blanco, 2007).

${ }^{23}$ Greenhow, Christine, Robelia, Beth, and Hughes, Joan E. (2009) "Web 2.0 and Classroom Research: What Path Should We Take Now?” en Educational Researcher Vol 38, N4: 246259. Véase también sobre la identidad y la vida online de los jóvenes Youth, Identity, and Digital Media. Edited by David Buckingham. The John D. and Catherine T. MacArthur Foundation Series on Digital Media and Learning. Cambridge, MA: The MIT Press, 2008 ${ }^{24}$ Caso 2, Registro $N^{\circ} 25$

25 "Culía” es un "chilenismo” como uso de palabra soez significa literalmente haberle introducido el pene por vía anal. Sin embargo no se utiliza en su sentido literal. "Wea” alude al órgano sexual masculino. "Hocicona” alude a la identificación de la boca con el hocico del animal, cuando una persona ha hablado más de la cuenta.

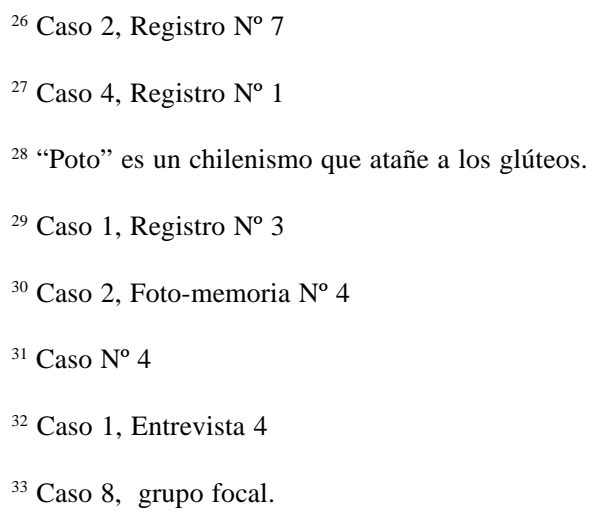

34 Deleuze sostiene el "dispositivo" es una estructura social que instala un conjunto multilíneal y bi-dimensional, de una máquina para hacer ver y para hacer hablar. Los dispo- 
sitivos están compuestos por líneas de visibilidad, enunciación, fuerza, subjetivación, ruptura, fisura, fractura, etc., que al entrecruzarse y mezclarse tienen capacidad de suscitar otras mediante variaciones de disposición. "Presentan líneas de fuerza que atraviesan umbrales en función de los cuales son estéticos, científicos, políticos, etc. Cuando la fuerza en un dispositivo en lugar de entrar en relación lineal con otra fuerza, se vuelve sobre sí misma y se afecta, no se trata de saber ni de poder, sino de un proceso de individuación relativo a grupos o personas que se sustrae a las relaciones de fuerzas establecidas como saberes constituidos...” Núñez Artola http://antroposmoderno.com/antro-articulo.php?id_articulo=137

${ }^{35}$ Putnam establece la diferencia entre cohesión social vincular y puente. Una hace referencia a grupos de igual capital cultural y social y la otra a ínter grupos de distinto emerger cultural y social.

${ }^{36}$ La naturaleza, dice Gleick, creó pautas y patrones; unos están ordenados en el espacio y desordenados en el tiempo, y otros, viceversa. No olvidar que las teorías del Big-Bang y los agujeros negros son expresiones cósmicas del caos” TORRES MARTÍNEZ, 2003.

${ }^{37}$ Bourdieu, ha definido el concepto de "habitus" como un "sistema de disposiciones durable, traspasable, estructuras estructuradas dispuestas a funcionar como estructuras estructurantes, esto es como principios de generación y estructuración de prácticas y representaciones..." Ver Bourdieu. Outline of a theory of practice. D Cambridge university press, 1977. p. 72 ..."Ver Bourdieu. Outline of a theory of practice. Cambridge University Press, 1977. p. 72. (N. del E.). en GUTIÉRREZ A. (2002): “Las prácticas sociales: una introducción a Pierre Bourdieu”. Tierra de nadie ediciones, Madrid.

${ }^{38}$ Expresión acuñada por Bauman para explicar los cambios de la modernidad sólida a la posmodernidad denominada líquida. 


\section{Bibliografía}

Angulo F.J.; Connell R.W.; Goodman J.; Kemmis S.; McLaren P.; Miller J. N.; Paraskeva J. (2008), Democracia, Educación y Participación en las Instituciones Educativas, $1^{\circ}$ Edición Morón, Sevilla, España.

Aple M.W.; Beane, J.A. (1997), Escuelas Democráticas, Reimpresión 2000, Editorial Morata, España.

Argot Madelein (2009), Coeducando para una ciudadanía en igualdad" Editorial Morata, Madrid, España.

Bhabha, Homi (2002), El lugar de la cultura Editorial Manantial, Buenos Aires, Argentina.

Balibar E. (2005), Violencias, Identidades y Civilidad. Para una cultura política y global”, Editorial Gedisa, S.A, Barcelona.

Bartolomé Pina M. (2002), Identidad y Ciudadanía. Un reto a la educación intercultural, Narcea, S.A de Ediciones, Madrid, España.

Bauman Zygmunt (2006), Comunidad. En busca de seguridad en un mundo hostil, Siglo XXI Editores $1^{\circ}$ edición, Madrid, España.

Ídem (2007), Miedo Líquido, Editorial Paidós, Argentina

Ídem (2006), Modernidad Líquida, Fondo de Cultura Económica, Argentina

Ídem (2007), Vida de Consumo, Fondo de Cultura Económica, Argentina

Bauman Zygmunt/ Keith Tester (2002), La ambivalencia de la Modernidad y otras conversaciones, Editorial Paidós, Barcelona, España.

García Canclini N. (2004), Diferentes, Desiguales y Desconectados, Editorial Gedisa S.A., Barcelona, España.

De Sousa Santos B. (2005), El Milenio Huérfano. Ensayos para una nueva cultura política, Editorial Trotta, Madrid, España.

Castoriadis, Cornelius (2007), Democracia y Relativismo, Editorial Trotta S.A, Madrid.

Castodiaris, Cornelius (2002), La insignificancia y la imaginación, Trotta, Madrid.

Cobo, R. (2008), Educar en la ciudadanía. Perspectivas Feministas, Los Libros de la Catarata, Madrid, España. 
Connell, R.W. (1997), Escuelas y justicia social, Reimpresión 1999 por Morata, España.

Cox, Cristián (2004), Educación y Cohesión Social en Latinoamérica: Signos Ambivalentes”, Comisión de Formación Ciudadana, Chile,

Cox Cristián: (2008), “Educación y cohesión social en Latinoamérica: Signos ambivalentes” en Tironi, Eugenio (editor) Redes, estado y mercados. Soportes de la cohesión social Latinoamericana. Editores Uqbar, Santiago. (417 pp.). El nombre del capítulo es: "Las reformas educativas y su impacto sobre la cohesión social en América Latina” (Capítulo 5, pp. 275321).

Fernández Lira C; Fernández Lira P.; Alegre Zahonero L. (2007), Educación para la Ciudadanía. Democracia , Capitalismo y Estado de Derecho, Edisiones Akal, Madrid.

Foucault M. (2009), Vigilar y castigar, segunda edición en Argentina, editorial siglo XXI.

Ídem (1990), Tecnologías del yo, Editorial Paidós, Barcelona.

Gimeno Sacristán, J (2001), Educar y convivir en la cultura global, Edit. Morata, Madrid.

Ídem (2000), La educación obligatoria: su sentido educativo y social, Ediciones Morata, Madrid.

Gutiérrez Alicia (2002), Las prácticas sociales: una introducción a Pierre Bourdieu, Tierradenadie ediciones, Madrid.

Hopenhayn, M. (2004), Cohesión social, una perspectiva en proceso de elaboración.

Ídem (2007), CEPAL, VVAAA: “Cohesión social en América Latina y el Caribe: Una revisión perentoria de algunas dimensiones”. Editores Ana Sojo y Andras Uthoff. Varios autores, entre ellos José Luis Machinea; Peter Abrahamson: Sonia Draibe y Manuel Riesco; Hans Jürgen Rösner; Juan Carlos Feres y Carlos Vergara: Eduardo Amadeo; Miguel Székely; Leonardo Garnier; Fernando Filgueira; Andras Uthoff; Adolfo Rodríguez Herrera; Oscar Cetrángolo; Juan Carlos Gómez-Sabaini; José Roberto Afonso; Juan Alberto Fuentes K.

Kincheloe J.L.; Steinberg SH. R.; Villaverde L.E. (2004), Repensar la inteligencia, Morata S.A., Madrid.

Martínez Rodríguez, Juan Bautista (2005), Educación para la Ciudadanía, Editorial Morata, España. 
Mires, Fernando (2001), “Civilidad” teoría politica de la postmodernidad Editorial Trotta, Madrid.

Ottone, Ernesto, “Del Desarrollo Social A La Cohesión Social: Algo Más Que Un Giro Semántico”, en Las Propuestas De La CEPAL. Ponencia preparada en colaboración con Martin Hopenhayn. Presentada en el Ciclo de Conferencias Tribuna de las Economías Latinoamericanas, 27-29 abril, Paris. IEA Civic Education Study database. La información de CIVICA por cada país se encuentra disponible en el siguiente link: http://www.iea.nl/ cived_datasets.html?\&no_cache=1\&sword_list[]=civic\&sword_list[]=dat

Pérez Gómez, A.I. (1999), La cultura escolar en la sociedad neoliberal, Edición Morata, segunda edición.

Peña, Carlos (2008), “El concepto de Cohesión social” en Tironi, Eugenio (editor) Redes, estado y mercados. Soportes de la cohesión social Latinoamericana. Editores Uqbar. Santiago.

Ídem (2007), El mal infinito, Crónica de “El Mercurio”, Reportajes D12, Domingo 10 de junio 2007.

PNUD (2002), Desarrollo Humano en Chile, Programa de las Naciones Unidas para el Desarrollo, Santiago.

Putnam, H. y Habermas J. (2008), Normas y Valores, Editorial Trotta, S.A., Madrid.

Putnam, Robert (2003,), El declive del capital social, Galaxia Gutenberg. España.

Redon, S. (2008), “Ciudadanía: Utopías y contradicciones en los procesos de formación del profesorado”. Revista de Cooperación Educativa Española: Monográfico de Educación para la ciudadanía: formación ética y política ISSN: 1133-0589 Septiembre-Noviembre 2008, No 90 http:// www.oei.es/15104.htm

Ídem (2006), La transversalidad en el currículum: Un estudio de caso”,Tesis doctoral Universidad de Cádiz España. Registrada en la biblioteca de la facultad de ciencias de la educación, Puerto real Cádiz y en la biblioteca mayor de la Pontificia Universidad Católica de Valparaíso.

Sennett Richard (2008), La cultura del nuevo capitalismo, Editorial Anagrama tercera edición, Barcelona España

Ídem (2006), La corrosión del carácter, novena edición Barcelona España.

Stake,R.E (1998), Investigación con estudios de caso, Editorial Morata. España. 
Sojo, A. y Uthoff, A. (2007), “Cohesión Social en América Latina y el Caribe: una revisión perentoria de algunas de sus dimensiones”. Comisión Económica para América Latina y el Caribe (CEPAL), coordinado por Tironi. Editores Uqbar, Santiago de Chile.

Spivak Gayatri (2009), Pueden hablar los subalternos, Editorial Museu d’Art Contemporani de Barcelona, España.

Subercaseaux B; Rojo G; Oyarzún K; Ruiz C; Martínez J.L.; Wallace D; Luongo G; Salomone A; Tala P; Castillo V; Baeza A. (2002), Identidades y sujetos. Para una discusión latinoamericana”, Ediciones Facultad de Filosofía y Humanidades, Universidad de Chile.

Sen, Amartya (2007), Identidad y violencia, Editorial Katz, Argentina.

Torres Martínez R. (2003), Los nuevos paradigmas en la actual revolución científica y tecnológica, Editorial Universidad estatal a distancia.

Touraine, Alain (1998), Igualdad y diversidad, Fondo de Cultura Económica; Colección Popular, Brasil el 2000.

Touraine, Alain: (1997), ¿Podremos vivir juntos?, Segunda re-impresión. Fondo de cultura económica, Argentina.

Valenzuela Eduardo (2007), Encuesta Latinoamérica de cohesión social principales resultados, Documento de trabajo

Valles, Miguel: (1997 ), Técnicas cualitativas de investigación social, Editorial Síntesis Psicología.

Varas, A.; Abregú M., Palacios M.; Lacoste J.P.; Delamaza G.; Fernández M.; Triveli C.; Asencio Hernández R.; Fuentes C.; Heiss C. (2006), La Propuesta Ciudadana. Una Relación Sociedad Civil-Estado, Fundación Ford Catalonia Ltda, Santiago de Chile.

Vega, María José (2004), Homi Bhabha, revista en línea Proyecto Apolo: http://turan.uc3m.es/uc3m/inst/LS/apolo/bhabha.html

Vidal Jiménez, R. (2005), Educación, poder y mercado: deconstrucción crítica de los efectos disciplinantes de las TIC en la nueva Escuela del Espectáculo, Comunicación, Saúde, Educación.

Recibido: 25.02.2010

Aceptado: 30.03.2011 